\title{
An inventory model with ramp type demand, time varying holding cost and price discount on
} backorders

\author{
Sujan Chandra ${ }^{a^{*}}$
}

${ }^{a}$ Department of Statistics, Haldia Government College, India

\begin{tabular}{l}
\hline C H R O N I C L E \\
\hline Article history: \\
Received April 2, 2016 \\
Received in revised format June \\
12, 2016 \\
Accepted July 212016 \\
Available online \\
July 212016 \\
\hline Keywords: \\
Time varying holding cost \\
Ramp type demand \\
Shortage \\
Price discount on backorder \\
\hline
\end{tabular}

A B S T R A C T

In this paper, an inventory model is studied with ramp type demand rate where holding cost is expressed as linearly increasing function of time. The study includes some features that are likely to be associated with certain types of inventory, like inventory of seasonal fruits and vegetables, newly launched fashion items, etc. When stock on hand is zero, the inventory manager offers a price discount to customers who are willing to backorder their demand. The optimum ordering policy and the optimum discount offered for each backorder are determined by minimizing the total cost in a replenishment interval.

(C) 2017 Growing Science Ltd. All rights reserved.

\section{Introduction}

In classical inventory models, the demand rate is assumed to be constant while in reality, time plays an important role in the inventory system. In the case of ramp type demand rate, the demand increases with time up to certain limit and then ultimately stabilizes and becomes constant. This type of demand rate is very commonly seen when some new brand of consumer goods comes to the market, for example, some kind of newly launched mobile phones, fashion goods, garments, automobiles, cosmetics, etc. Hill (1995) first considered the inventory models for increasing demand followed by a constant demand. Mandal and Pal (1998) extended the Hill's inventory model for deteriorating items and allowing shortage. Wu et al. (1999) constructed the inventory model with ramp type demand rate such that the inventory period is longer than the linear increasing period of the demand. Wu (2001) investigated the inventory model with ramp type demand rate and Weibull deterioration rate. Giri et al. (2003) developed an inventory model with ramp type demand and more generalized Weibull deterioration distribution. Panda et al. (2008) gave an optimal replenishment policy for the perishable seasonal product in a season with ramp type demand rate. Sharma et al. (2009) developed an economic order quantity (EOQ) model for variable rate of deterioration having a ramp type demand rate. Mandal

* Corresponding author

E-mail address: chandra.sujan@gmail.com (S. Chandra)

C 2017 Growing Science Ltd. All rights reserved.

doi: $10.5267 /$ j.uscm.2016.7.003 
(2010) derived an EOQ model for deteriorating items, assuming a ramp type demand rate. Pradhan and Tripathy (2012) developed an interactive inventory model between producer and buyer in the presence of an extraordinary purchase and the credit period with Weibull deterioration for items and ramp type demand. In most models, holding cost is known and constant. But holding cost may not always be constant. In case of seasonal fruits and vegetables, the longer these items are kept in storage, the more sophisticated the storage facilities and services needed, and therefore, the higher the holding cost. The variability in the holding cost was first introduced by Muhlemann and Valtis-Spanopoulous (1980). They developed an EOQ model with a constant demand rate where holding cost is expressed as a percentage of the average value of capital invested in the stock. Weiss (1982) discussed the same model considering holding cost per unit as a nonlinear function of the length of time for which the item was held in stock. Goh (1994) considered two types of holding cost variation: (a) a nonlinear function of storage time and (b) a nonlinear function of storage level. Giri et al. (1996) developed a generalized EOQ model for deteriorating items with shortages, in which both the demand rate and the holding cost are continuous functions of time. Alfares (2007) presented an inventory system with stock dependent demand, in which the holding cost is a step function of storage time. He considered two types of holding cost variation in terms of storage time: retroactive increase, and incremental increase. Roy (2008) developed an inventory model for deteriorating items by considering demand rate and holding cost as linear functions of time.

In classical inventory models with shortages, it is generally assumed that the unmet demand is either completely lost or completely backlogged. However, it is quite possible that while some customers leave, others are willing to wait till the fulfilment of their demand. In some situations, the inventory manager may offer a discount on backorders and/or reduction in waiting time to tempt customers to wait. Pan and Hsiao (2001) proposed a continuous review inventory model by considering the order quantity and with negotiable backorders as decision variables. Ouyang et al. (2003) developed a periodic review inventory model with backorder discounts to accommodate more practical features of the real inventory systems. Chuang et al. (2004) discussed a distribution free procedure for mixed inventory model with backorder discount and variable lead time. Uthayakumar and Parvati (2008) considered a model with only first two moments of the lead time demand known, and obtained the optimum backorder price discount and order quantity in that situation. Pal and Chandra (2012) studied a deterministic inventory model with shortages. They considered only a fraction of the unmet demand is backlogged, and the inventory manager offers a discount on it. Pal and Chandra (2014) developed a periodic review inventory model with stock dependent demand, permissible delay in payment and price discount on backorders.

In this paper, an inventory model is developed where holding cost is expressed as linearly increasing function of time and demand rate is a ramp type function of time. The manager offers his customer a discount in case he is willing to backorder his demand when there is a stock-out. The paper is organized as follows. Assumptions and notations are presented in Section 2. In Section 3, the model is formulated and the optimal order quantity and backorder price discount determined. In Section 4, numerical examples are cited to illustrate the policy and to analyze the sensitivity of the model with respect to the model parameters. Concluding remarks are given in Section 5.

\section{Notations and Assumptions}

To develop the model, we use the following notations and assumptions.

\section{Notations}

$I(t)=$ inventory level at time point $t$

$b=$ fraction of the demand backordered during stock out

$b_{0}=$ upper bound of backorder ratio

$K=$ ordering cost per order

$P=$ purchase cost per unit 
$s_{1}=$ backorder cost per unit backordered per unit time

$s_{2}=$ cost of a lost sale

$\pi=$ price discount on unit backorder offered

$\pi_{0}=$ marginal profit per unit

$T=$ length of a replenishment cycle

$T_{1}=$ time taken for stock on hand to be exhausted, $0<T_{1}<T$

$S=$ maximum stock height in a replenishment cycle

$s=$ shortage at the end of a replenishment cycle

\section{Assumptions}

1. The model considers only one item in inventory.

2. Replenishment of inventory occurs instantaneously on ordering, that is, lead time is zero.

3. Shortages are allowed, and a fraction $b$ of unmet demands during stock-out is backlogged.

4. Holding cost $h(t)$ per item per unit time is assumed to be time dependent

$$
h(t)=h+\alpha t \quad \text { where } \alpha>0, h>0
$$

5. The demand rate $R(t)$ is assumed to be a ramp type function of time $t$

$$
R(t)=D_{0}[t-(t-\mu) H(t-\mu)]
$$

where $D_{0}$ and $\mu$ are positive constants and $H(t-\mu)$ is the Heaviside's function defined as

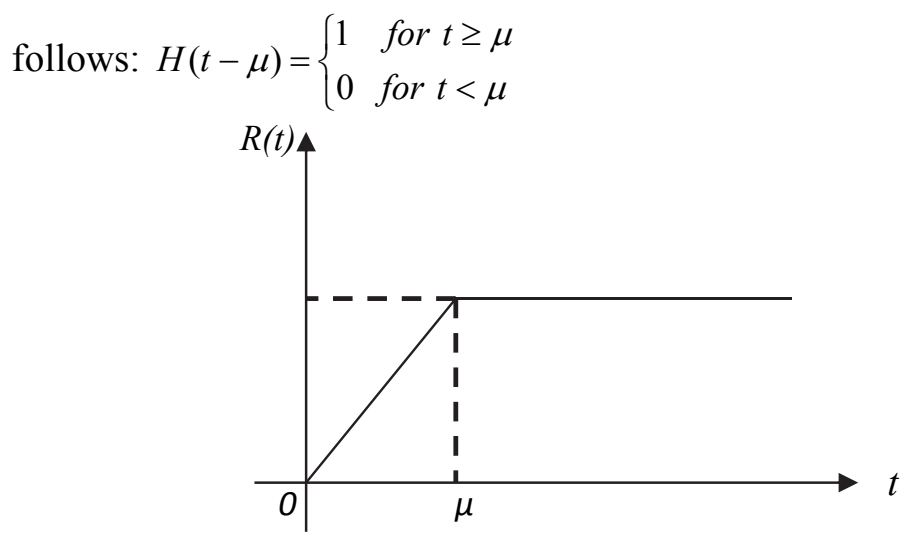

Fig. 1. The ramp type demand rate

6. The time taken for stock on hand to be exhausted $\left(T_{l}\right)$ is greater than $\mu$.

7. During the stock-out period, the backorder fraction $b$ is directly proportional to the price discount $\pi$ offered by the inventory manager. Thus,

$$
b=\frac{b_{0}}{\pi_{0}} \pi, \text { where } 0 \leq b_{0} \leq 1,0 \leq \pi \leq \pi_{0}
$$

\section{Model Formulation}

The planning period is divided into reorder intervals, each of length $T$ units. Orders are placed at time points $0, T, 2 T, 3 T, \ldots$, the order quantity being just sufficient to bring the stock height to a certain maximum level $S$. Depletion of inventory occurs due to demand during the period $\left(0, T_{1}\right), T_{1}<T$, and in the interval $\left(T_{1}, T\right)$ shortage occurs, of which a fraction $b$ is backlogged. Hence, the variation in inventory level with respect to time is given by

$$
\frac{d}{d t} I(t)= \begin{cases}-D_{0} t, & \text { if } 0<t<\mu \\ -D_{0} \mu, & \text { if } \mu<t<T_{1} \\ -b D_{0} \mu, & \text { if } T_{1}<t<T\end{cases}
$$

Since $I(0)=S$ and $I\left(T_{1}\right)=0$, we get 


$$
I(t)=\left\{\begin{array}{cc}
-\frac{D_{0} t^{2}}{2}+S, & \text { if } 0<t<\mu \\
D_{0} \mu\left(T_{1}-t\right), & \text { if } \mu<t<T_{1} \\
b D_{0} \mu\left(T_{1}-t\right), & \text { if } T_{1}<t<T
\end{array}\right.
$$

Hence,

$$
S=\frac{D_{0} \mu}{2}\left(2 T_{1}-\mu\right) \text { and } s=b D_{0} \mu\left(T-T_{1}\right)
$$

Then,

Ordering cost during a cycle $(\mathrm{OC})=K$

Holding cost of inventories during a cycle (HC)

$$
=\int_{0}^{T_{1}} h(t) I(t) d t=\int_{0}^{\mu} h(t) I(t) d t+\int_{\mu}^{T_{1}} h(t) I(t) d t=\frac{1}{6} D_{0} \mu \alpha T_{1}^{3}+\frac{1}{2} D_{0} \mu h T_{1}^{2}-\frac{1}{6} D_{0} \mu^{3} h-\frac{1}{24} D_{0} \mu^{4} \alpha
$$

Backorder cost during a cycle (BC)

$$
=-S_{1} \int_{T_{1}}^{T} I(t) d t=\frac{S_{1} b D_{0} \mu}{2}\left(T-T_{1}\right)^{2}
$$

Lost sales cost during a cycle $(\mathrm{LC})=(1-b) D_{0} \mu\left(T-T_{1}\right)$

Purchase cost of inventory during a cycle is (PC)

$$
=P\left(\frac{D_{0} \mu}{2}\left(2 T_{1}-\mu\right)+b D_{0} \mu\left(T-T_{1}\right)\right)
$$

Hence, the cost per unit length of a replenishment cycle is given by

$$
\begin{aligned}
C\left(T_{1}, T, b\right) & =\frac{1}{T}[\mathrm{OC}+\mathrm{HC}+\mathrm{BC}+\mathrm{LC}+\mathrm{PC}] \\
= & \frac{1}{T}\left(\begin{array}{l}
K+\frac{1}{6} D_{0} \mu T_{1}^{2}\left(\alpha T_{1}-3 h\right)-\frac{1}{24} D_{0} \mu^{3}(\alpha \mu+4 h) \\
+\frac{1}{2} D_{0} \mu\left(T-T_{1}\right)\left(s_{1} b\left(T-T_{1}\right)+2 b\left(P-s_{2}\right)+2 s_{2}\right)+\frac{1}{2} D_{0} \mu P\left(2 T_{1}-\mu\right)
\end{array}\right)=\frac{N\left(T_{1}, T, b\right)}{T}
\end{aligned}
$$

The optimal values of $T_{1}, T$ and $b$, which minimize $C\left(T_{1}, T, b\right)$, must satisfy the following equations:

$$
\begin{aligned}
& \left(\frac{1}{2} \alpha T_{1}+h+s_{1} b\right) T_{1}=s_{1} b T+(1-b)\left(s_{2}-P\right) \\
& D_{0} \mu\left(s_{1} b\left(T-T_{1}\right)+b\left(P-s_{2}\right)+s_{2}\right)=C\left(T_{1}, T, b\right) \\
& T-T_{1}=\frac{2\left(s_{2}-P\right)}{s_{1}}
\end{aligned}
$$

Result 3.1: For given $T$ and $b, C\left(T_{1}, T, b\right)$ is a convex function of $T_{1}$.

Proof: We have

$$
\frac{\partial^{2} C\left(T_{1}, T, b\right)}{\partial T_{1}^{2}}=\frac{D_{0} \mu}{T}\left(\alpha T_{1}+h+s_{1} b\right)>0
$$

Hence, the result.

Result 3.2: For given $T_{1}$ and $b, C\left(T_{1}, T, b\right)$ is convex in $T$. 
Proof:

$$
\frac{\partial}{\partial T} C(T)=0 \text { gives }-\frac{N}{T^{2}}+\frac{1}{T} \frac{\partial N}{\partial T}=0 \Rightarrow N=T \frac{\partial N}{\partial T}, \text { where } \mathrm{N} \text { is the numerator of } C(T)
$$

So, for any $T$ satisfying $\frac{\partial}{\partial T} C(T)=0$,

$$
\frac{\partial^{2}}{\partial T^{2}} C(T)=\frac{2 N}{T^{3}}-\frac{1}{T^{2}} \frac{\partial N}{\partial T}-\frac{1}{T^{2}} \frac{\partial N}{\partial T}+\frac{1}{T} \frac{\partial^{2} N}{\partial T^{2}}=\frac{1}{T} \frac{\partial^{2} N}{\partial T^{2}}=\frac{s_{1} b D_{0} \mu}{T}>0
$$

This is possible only if $C(T)$ is convex in $T$.

Hence the result.

\section{Numerical Illustration and Sensitivity Analysis}

Since it is difficult to find closed form solutions to the sets of Eqs. (1-3), we numerically find solutions to the equations for given sets of costs using the statistical software MATLAB. The following tables show the change in optimal inventory policy with change in a model parameter, when the other parameters remain fixed.

Table 1

The optimal inventory policy for different values of $h$, when $K=500, D_{0}=100, \alpha=0.6, P=5, \mu=$ $0.25, s_{1}=6$ and $s_{2}=7$

\begin{tabular}{ccccc}
\hline$h$ & $T_{1}$ & $T$ & $b$ & $C\left(T_{1}, T, b\right)$ \\
\hline 3 & 2.63 & 3.30 & 0.2992 & 374.28 \\
5 & 2.09 & 2.76 & 0.3775 & 419.64 \\
7 & 1.75 & 2.42 & 0.7080 & 454.89 \\
8 & 1.63 & 2.29 & 0.7354 & 469.90 \\
9 & 1.52 & 2.18 & 0.7267 & 483.56 \\
\hline
\end{tabular}

\section{Table 2}

The optimal inventory policy for different values of $s$, when $K=500, D_{0}=100, \alpha=0.6, P=5, \mu=$ $0.25, h=4$ and $s_{2}=7$

\begin{tabular}{ccccc}
\hline$s_{1}$ & $T_{1}$ & $T$ & $b$ & $C\left(T_{1}, T, b\right)$ \\
\hline 4 & 2.16 & 3.16 & 0.7148 & 375.57 \\
8 & 2.42 & 2.92 & 0.3451 & 411.50 \\
10 & 2.48 & 2.88 & 0.3767 & 419.78 \\
14 & 2.56 & 2.84 & 0.2573 & 429.75 \\
15 & 2.57 & 2.84 & 0.2354 & 431.46 \\
\hline
\end{tabular}

\section{Table 3}

The optimal inventory policy for different values of $s 2$, when $K=500, D_{0}=100, \alpha=0.6, P=5, \mu=$ $0.25, h=4$ and $s_{1}=6$

\begin{tabular}{ccccc}
\hline$s_{2}$ & $T_{1}$ & $T$ & $b$ & $C\left(T_{1}, T, b\right)$ \\
\hline 8 & 2.22 & 3.22 & 0.3307 & 383.41 \\
13 & 2.26 & 4.92 & 0.3340 & 389.05 \\
14 & 2.33 & 5.33 & 0.3333 & 399.18 \\
16 & 2.51 & 6.18 & 0.6875 & 423.90 \\
20 & 2.94 & 7.94 & 0.7202 & 484.45 \\
\hline
\end{tabular}

\section{Table 4}

The optimal inventory policy for different values of $P$, when $K=500, D_{0}=100, h=4, \alpha=0.6, \mu=$ $0.25, s_{1}=6$ and $s_{2}=7$

\begin{tabular}{ccccc}
\hline$P$ & $T_{1}$ & $T$ & $b$ & $C\left(T_{1}, T, b\right)$ \\
\hline 1 & 2.18 & 4.18 & 0.3327 & 278.43 \\
2 & 2.16 & 3.82 & 0.4141 & 300.74 \\
3 & 2.17 & 3.50 & 0.4955 & 327.30 \\
4 & 2.22 & 3.22 & 0.3333 & 359.39 \\
6 & 2.50 & 2.83 & 0.2139 & 446.50 \\
\hline
\end{tabular}


Table 5

The optimal inventory policy for different values of $\alpha$, when $K=500, D_{0}=100, h=4, P=5, \mu=0.25$, $s_{1}=6$ and $s_{2}=7$

\begin{tabular}{ccccc}
\hline$\alpha$ & $T_{1}$ & $T$ & $b$ & $C\left(T_{1}, T, b\right)$ \\
\hline 0.1 & 2.56 & 3.22 & 0.3060 & 388.84 \\
0.5 & 2.37 & 3.03 & 0.3137 & 396.76 \\
1.1 & 2.17 & 2.84 & 0.3460 & 406.64 \\
1.9 & 1.99 & 2.65 & 0.4133 & 417.48 \\
2.3 & 1.92 & 2.58 & 0.6061 & 422.21 \\
\hline
\end{tabular}

The above tables show that, for other parameters remaining constant,

(a) both $T_{1}$ and $T$ are decreasing in $h$ and $\alpha$ but increase as $s_{2}$ increase;

(b) $b$, and hence $\pi$, decreases with increase in $s_{1}$, but increases with $h, s_{2}$ and $\alpha$;

(c) $T_{1}$ is increasing in $s_{1}, s_{2}$ while $T$ is decreasing in $h, P$ and $s_{1}$.

The above observations also indicate that, with the aim to minimizing total cost, the policy should be to maintain high inventory level for low holding cost and purchase cost but high lost sales cost. Also, higher the backorder cost, lower should be the price discount offered and for higher lost sales cost, higher price discount should be offered.

Table 6 gives the percentage change in the total cost over an inventory cycle with change in the model parameters.

Let us consider the following model parameters: $K=500, D_{0}=100, \alpha=0.6, P=5, \mu=0.25, h=4, s 1$ $=6$ and $s_{2}=7$. Table 6 gives the percentage change in the total cost over an inventory cycle with change in the model parameters.

\section{Table 6}

Percentage change in total cost with change in the model parameters

\begin{tabular}{|c|c|c|c|c|c|}
\hline \multicolumn{2}{|c|}{ Parameter } & \multirow[t]{2}{*}{$\%$ change in total cost } & \multicolumn{2}{|c|}{ Parameter } & \multirow[t]{2}{*}{$\%$ change in total cost } \\
\hline Name & Value & & Name & Value & \\
\hline \multirow{5}{*}{$h$} & 3 & -6.09 & \multirow{5}{*}{$s_{1}$} & 4 & -5.77 \\
\hline & 5 & 5.29 & & 8 & 3.25 \\
\hline & 7 & 14.14 & & 10 & 5.33 \\
\hline & 8 & 17.90 & & 14 & 7.83 \\
\hline & 9 & 21.33 & & 15 & 8.26 \\
\hline \multirow{5}{*}{$P$} & 1 & -30.14 & \multirow{5}{*}{$s_{2}$} & 8 & -3.80 \\
\hline & 2 & -24.54 & & 13 & -2.38 \\
\hline & 3 & -17.88 & & 14 & 0.16 \\
\hline & 4 & -9.83 & & 16 & 6.36 \\
\hline & 6 & 12.03 & & 20 & 21.55 \\
\hline \multirow{5}{*}{$\alpha$} & 0.1 & -2.43 & & & \\
\hline & 0.5 & -0.45 & & & \\
\hline & 1.1 & 2.03 & & & \\
\hline & 1.9 & 4.75 & & & \\
\hline & 2.3 & 5.94 & & & \\
\hline
\end{tabular}

From the results of Table 6, it is quite evident that the model is highly sensitive to changes in the holding cost, purchase cost and lost sales cost compare to other model parameters.

Sensitivity analysis is performed by changing (increasing or decreasing) the parameters by $5 \%$ and $10 \%$ and taking one parameter at a time, keeping the remaining parameters at their original values. The results are shown in Table 7 as follows. 
Table 7

The results of sensitivity analysis

\begin{tabular}{|c|c|c|c|c|}
\hline Parameter & $\%$ change & $\%$ change in $T_{1}$ & $\%$ change in $T$ & $\%$ change in $b$ \\
\hline \multirow{4}{*}{$h$} & -10 & 4.78 & 3.72 & 58.75 \\
\hline & -5 & 2.33 & 1.81 & 59.10 \\
\hline & 5 & -2.21 & -1.72 & 28.36 \\
\hline & 10 & -4.32 & -3.36 & 60.30 \\
\hline \multirow{4}{*}{$s_{1}$} & -10 & -1.73 & 1.13 & 20.45 \\
\hline & -5 & -0.83 & 0.53 & 28.18 \\
\hline & 5 & 0.76 & -0.47 & 59.86 \\
\hline & 10 & 1.46 & -0.89 & 58.88 \\
\hline \multirow{4}{*}{$s_{2}$} & -10 & 5.00 & -3.90 & 37.70 \\
\hline & -5 & 2.32 & -2.09 & 22.86 \\
\hline & 5 & -1.99 & 2.35 & 83.10 \\
\hline & 10 & -3.65 & 4.95 & 42.62 \\
\hline \multirow{4}{*}{$P$} & -10 & -2.58 & 3.56 & 145.58 \\
\hline & -5 & -1.37 & 1.72 & 12.08 \\
\hline & 5 & 1.54 & -1.59 & 25.27 \\
\hline & 10 & 3.26 & -3.03 & 21.45 \\
\hline \multirow{4}{*}{$\alpha$} & -10 & 0.98 & 0.76 & 30.50 \\
\hline & -5 & 0.48 & 0.38 & 30.39 \\
\hline & 5 & -0.47 & -0.37 & 30.20 \\
\hline & 10 & -0.94 & -0.73 & 30.86 \\
\hline
\end{tabular}

\section{Conclusion}

The paper studies an inventory model with ramp type demand allowing shortages. It is also considered that holding cost is linearly increasing function of time. The study includes some features that are likely to be associated with certain types of inventory in real life, like inventory of seasonal fruits and vegetables, newly launched fashion items, electronic goods, etc. A fraction of the demand is backlogged, and the inventory manager offers a discount to each customer who is ready to wait till fulfilment of his demand. The optimum ordering policy and the optimum discount offered for each backorder are determined by minimizing the total cost in a replenishment interval. Through numerical study, it is observed that for low backorder cost, it is beneficial to the inventory manager to offer the customers high discount on backorders.

\section{Acknowledgement}

The author wishes to acknowledge the anonymous reviewer for his/her helpful comments to the manuscript. The author gratefully acknowledges the support of the University Grants Commission for Minor Research Project (F.No.PSW-134/14-15 (ERO) dated 03.02.2015).

\section{References}

Alfares, H. K. (2007). Inventory model with stock-level dependent demand rate and variable holding cost. International Journal of Production Economics, 108(1), 259-265.

Chuang, B. R., Ouyang, L. Y., \& Chuang, K. W. (2004). A note on periodic review inventory model with controllable setup cost and lead time.Computers \& Operations Research, 31(4), 549-561.

Giri, B. C., Jalan, A. K., \& Chaudhuri, K. S. (2003). Economic order quantity model with Weibull deterioration distribution, shortage and ramp-type demand. International Journal of Systems Science, 34(4), 237-243.

Giri, B. C., Goswami, A., \& Chaudhuri, K. S. (1996). An EOQ model for deteriorating items with time varying demand and costs. Journal of the Operational Research Society, 47(11), 1398-1405.

Goh, M. (1994). EOQ models with general demand and holding cost functions. European Journal of Operational Research, 73(1), 50-54. 
Hill, R. M. (1995). Inventory models for increasing demand followed by level demand. Journal of the Operational Research Society, 46(10), 1250-1259.

Mandal, B. (2010). An EOQ inventory model for Weibull distributed deteriorating items under ramp type demand and shortages. Opsearch, 47(2), 158-165.

Mandal, B., \& Pal, A. K. (1998). Order level inventory system with ramp type demand rate for deteriorating items. Journal of interdisciplinary Mathematics, 1(1), 49-66.

Muhlemann, A. P., \& Valtis-Spanopoulos, N. P. (1980). A variable holding cost rate EOQ model. European Journal of Operational Research, 4(2), 132-135.

Ouyang, L. Y., Chuang, B. R., \& Lin, Y. J. (2003). Impact of backorder discounts on periodic review inventory model. International Journal of Information and Management Sciences, 14(3), 1-14.

Pal, M., \& Chandra, S. (2012). A deterministic inventory model with permissible delay in payment and price discount on backorders. Opsearch,49(3), 271-279.

Pal, M., \& Chandra, S. (2014). A periodic review inventory model with stock dependent demand, permissible delay in payment and price discount on backorders. Yugoslav Journal of Operations Research, 24(1), 99-110.

Pan, J. C. H., \& Hsiao, Y. C. (2001). Inventory models with back-order discounts and variable lead time. International Journal of Systems Science,32(7), 925-929.

Panda, S., Senapati, S., \& Basu, M. (2008). Optimal replenishment policy for perishable seasonal products in a season with ramp-type time dependent demand. Computers \& Industrial Engineering, 54(2), 301-314.

Pradhan, S., \& Tripathy, P.K. (2012). Inventory model for ramp type items with trade credit under extra ordinary purchase, IOSR Journal of Mathematics, 2(6), 1-09.

Roy, A. (2008). An inventory model for deteriorating items with price dependent demand and time varying holding cost. Advanced modeling and optimization, 10(1), 25-37.

Sharma, M. M., Goel, V. C., \& Yadav, R. K. (2009). An order-level inventory model for decaying items with ramp type demand, and partial backlogging.International Transactions in Mathematical Sciences and Computer, 2, 157-166.

Uthayakumar, R., \& Parvathi, P. (2008). Inventory models with mixture of backorders involving reducible lead time and setup cost. Opsearch, 45(1), 12.

Weiss, H. J. (1982). Economic order quantity models with nonlinear holding costs. European Journal of Operational Research, 9(1), 56-60.

Wu, J. W., Lin, C., Tan, B., \& Lee, W. C. (1999). An EOQ inventory model with ramp type demand rate for items with Weibull deterioration. International Journal of Information and Management Sciences, 10(3), 41-51.

Wu, K. S. (2001). An EOQ inventory model for items with Weibull distribution deterioration, ramp type demand rate and partial backlogging. Production Planning \& Control, 12(8), 787-793.

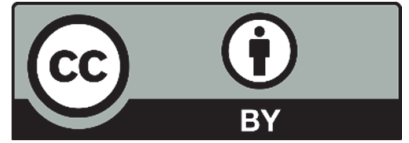

(C) 2016 by the authors; licensee Growing Science, Canada. This is an open access article distributed under the terms and conditions of the Creative Commons Attribution (CC-BY) license (http://creativecommons.org/licenses/by/4.0/). 